EPJ Web of Conferences 56, 04001 (2013)

DOI: $10.1051 /$ epjconf/20135604001

(C) Owned by the authors, published by EDP Sciences, 2013

\title{
Surface Tests to Demonstrate the Construction Feasibility of the Belgian Supercontainer
}

\author{
L. Areias ${ }^{1}$, R. Gens ${ }^{2}$, P. Van Marcke ${ }^{2}$, H. Van Humbeeck ${ }^{2}$, L. Villers ${ }^{3}$ and A. Van Cotthem ${ }^{3}$ \\ ${ }^{1}$ EIG EURIDICE, c/o SCK $•$ CEN, Boeretang 200, 2400 Mol, Belgium \\ ${ }^{2}$ ONDRAF/NIRAS, Avenue des Arts 14, 1210 Brussels, Belgium \\ ${ }^{3}$ Technum-Tractebel Engineering, Avenue Ariane 7, 1200 Brussels, Belgium
}

\begin{abstract}
The Supercontainer (SC) is a reference concept, adopted by the Belgian Agency for Radioactive Waste and Enriched Fissile Materials (ONDRAF/NIRAS), for the packaging of high level vitrified radioactive waste (HLW) and spent fuel (SF). The waste package consists of different components all designed to fulfil specific functions. One of these is a carbon steel overpack developed to prevent contact of the waste with the engineered barrier system and the host geological formation during the thermal phase. Another is a concrete buffer and cementitious filler, both developed to provide a high $\mathrm{pH}$ environment during at least the thermal phase, which ensures passivation of the overpack and provides radiological shielding during construction and handling of the SC. Finally, the presence of an outer steel envelope serves as a mould for the casting of the outer buffer while providing additional mechanical strength and confinement during transportation and handling of the waste package. As part of the first safety and feasibility case (SFC-1), ONDRAF/NIRAS has to demonstrate that no fundamental flaws exist regarding the feasibility to construct the SC. To this end, ONDRAF/NIRAS established a research programme consisting of desk studies, modelling, theoretical development and experimental testing. The primary objective of the experimental testing programme is to demonstrate the feasibility to construct the $\mathrm{SC}$. This paper describes the test's setup and design and provides a summary of the main observations obtained during an experimental test performed to evaluate the construction feasibility of the SC.
\end{abstract}

\section{Introduction}

In the reference concept of the SC (Figure 1) canisters containing vitrified HLW or SF assemblies are encapsulated in a watertight carbon steel overpack and then cast in a concrete matrix surrounded by an outer steel envelope $[1,2,3]$. The SF assemblies consist of uranium oxide $\left(\mathrm{UO}_{\mathrm{x}}\right)$ and mixed oxide $\left(\mathrm{MO}_{\mathrm{x}}\right)$. The construction of the $\mathrm{SC}$ has four stages, as shown in Figure 2. Stage 1 comprises the installation of the steel envelope and construction of the first concrete buffer. During this construction stage there is no contact with the radioactive waste. Stage 2 is the installation of the overpack containing one or more canisters with HLW or SF. Stage 3 is the construction of buffer phase 2, also called the 'filler', which consists of a cementitious mortar. The filler has a composition similar to that of the buffer except for the matrix aggregates, which have a finer grain size. Finally,

This is an Open Access article distributed under the terms of the Creative Commons Attribution License 2.0, which permits unrestricted use, distribution, and reproduction in any medium, provided the original work is properly cited. 
the SC is completed with a concrete cover in stage 4 . Stages 2 to 4 occur in contact with the waste and are termed 'hot cell' construction stages.

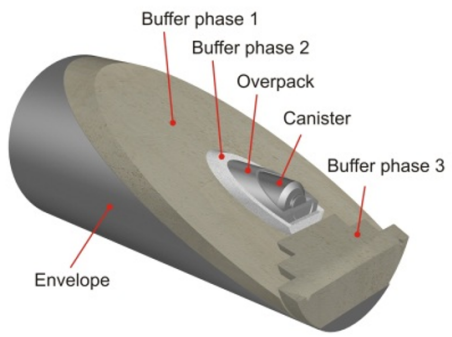

Fig. 1. Belgian reference concept of a Supercontainer for the final disposal of HLW and SF assemblies.

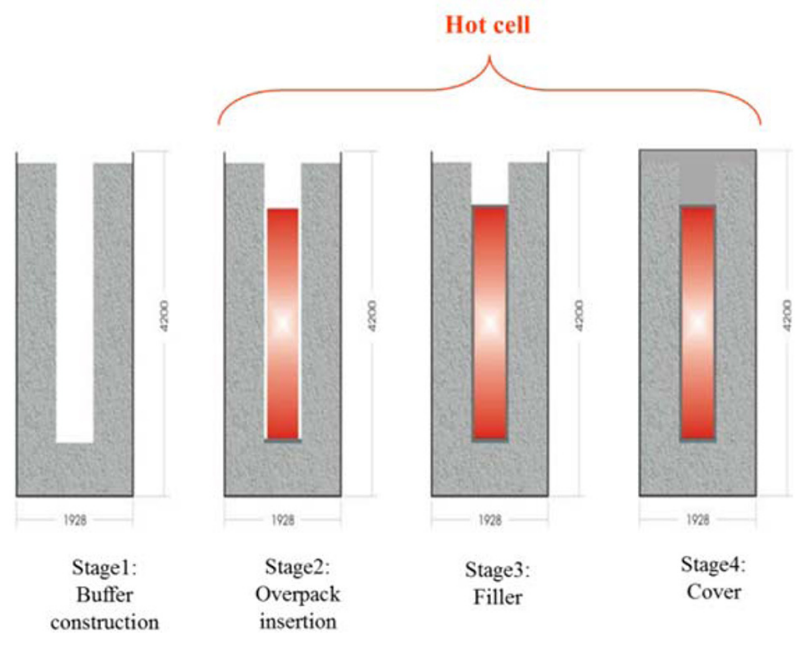

Fig. 2. The four construction stages of a Supercontainer.

The SC will be constructed at the surface and disposed of in a deep geological clay layer. As shown in Figure 1, the SC is based on a multiple barrier system. Each component of the SC has a specific safety function or role requirement. The concrete buffers provide structural confinement for the overpack as well as radiological shielding during construction and transportation to the repository. In addition, they provide the high alkaline conditions needed to ensure passivation of the carbon steel overpack. The long-term safety function of the overpack is to contain the radionuclides during the thermal phase. The thermal phase is the period during which the radioactive waste will continue to generate significant amounts of heat and will last several hundreds of years.

The experimental test described in this paper was performed in 2009 [3] using a half-scale model of the SC. The half-scale test has a true horizontal scale but is limited in height to approximately half of a real SC. The reduced height was necessary to accommodate the overhead space available at the laboratory where the test was performed, which has a maximum working height of $7 \mathrm{~m}$. This limited the height of the test to $3.45 \mathrm{~m}$.

\section{Objectives}

The objectives of the half-scale test include the validation of modeling studies performed earlier to study the early-age thermo-mechanical behavior of the concrete components [4], the testing of the 
interface between the filler and the metal overpack, the evaluation of operational aspects of construction and the assessment of the construction feasibility of the SC.

\section{Test design}

\subsection{Buffer}

A cross-section of the outer buffer constructed for the half-scale test appears in Figure 3. The buffer consists of non-reinforced, self-compacting concrete (SCC) made using Portland cement and limestone aggregates with a water/cement ratio of 0.5 . The composition of the concrete buffer appears in Table 1. One of the principal functions of the concrete is to provide a high $\mathrm{pH}$ environment to ensure the passivation of the carbon steel overpack during at least the thermal phase. A description of the physical properties of the concrete appears in [3, 4].
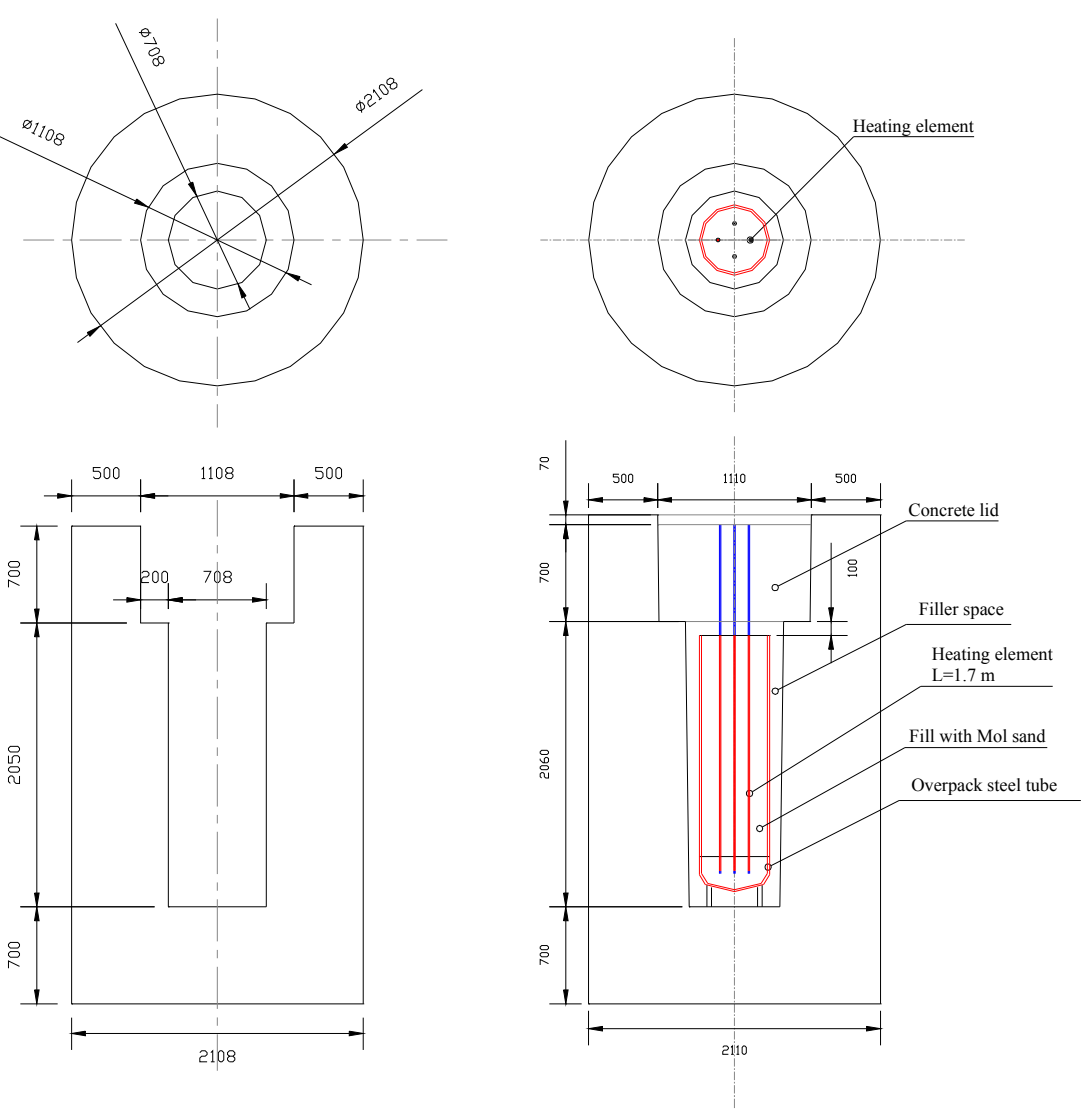

Fig. 3. Cross-section through the concrete buffer phase 1 [left $]$ and details of heater [right]. Dimensions in [m].

For this test, both buffer phases 1 and 2 used the same concrete composition. This was done for practical reasons in order to simplify the test. In the real SC, buffer phase 2 is a mortar with similar composition but a smaller-size fraction than the concrete of buffer phase 1. Its primary functions are to fill the space between buffer phase 1 and the overpack, to improve the heat transfer properties of 
the Supercontainer and to provide further passivation of the carbon steel overpack. Finally, the outer steel envelope serves as a mould and provides additional mechanical strength and confinement during transportation and handling of the SC.

Table 1. Composition of SCC buffer used in half-scale test

\begin{tabular}{|c|c|}
\hline Component & Kg/m3 \\
\hline Cement CEMI/42.5N HSR LA LH & 350 \\
\hline Calcitec 2001 MS & 100 \\
\hline Calcareous aggregate & \\
\hline $0 / 4$ & 840 \\
\hline $2 / 6$ & 327 \\
\hline $6 / 14$ & 559 \\
\hline Plasticizer & $10-14$ \\
\hline Water & 175 \\
\hline W/C ratio & 0.5 \\
\hline
\end{tabular}

The half-scale test was performed following the same construction stages outlined previously in Figure 2. In the first stage the outer concrete buffer was allowed to cure for a minimum of 28 days. The curing took place at ambient conditions and with the outer mould installed. In the second stage a heater system was installed to simulate a real overpack containing HLW. For practical reasons, the filler and lid in stages 3 and 4, respectively were constructed with a SCC mixture identical to the one used to make the outer concrete buffer.

\subsection{Overpack and heat source}

The general installation details of the metal overpack and heat source appear in Figures 3, 4 and 5. The carbon steel overpack has a diameter of $508 \mathrm{~mm}$ and a thickness of $15.06 \mathrm{~mm}$. Inside the overpack are four heating elements to simulate the thermal heat output normally generated by the radioactive waste in a real overpack.

After installing the heating elements, the simulated overpack is filled with fine grained, clean Mol sand. The sand is a good heat conductor and helps create a homogeneous heat distribution inside the overpack. Figure 4 shows the heater system during installation. The overpack is pre-heated before the start of the second construction stage.
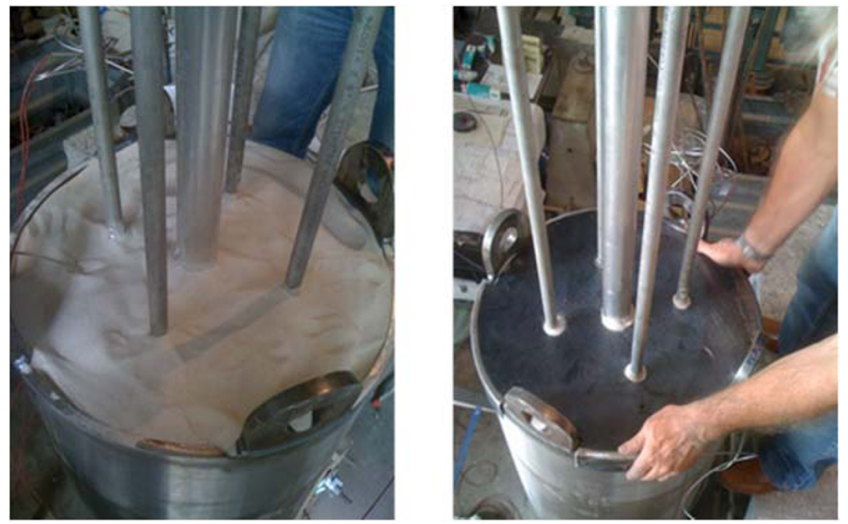

Fig. 4. Overpack with installed heater elements surrounded by Mol sand. 
Figure 5 shows the heat source setup. It consists of four identical heat probes each containing a heated length of $1400 \mathrm{~mm}$. The heating elements were custom designed for the test. They were operated to generate heat under a constant power of $300 \mathrm{~W} / \mathrm{m}$ length of overpack. This is the power normally generated by a real overpack containing vitrified HLW.

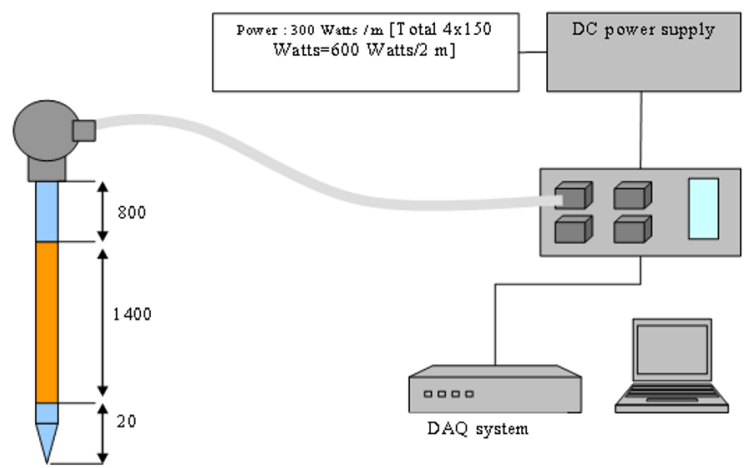

Fig. 5. Heat source setup.

\subsection{Parameters monitored}

Table 2 contains the list of parameters monitored during the $1 / 2$-scale test. The test was performed in the laboratory. The monitored parameters include the ambient wind velocity, temperature and relative humidity in the laboratory in the vicinity of the test, as well as temperature, displacement and strain in the concrete buffer. A typical instrumentation plan appears in Figure 6.

Table 2. Monitoring parameters and instrumentation in the half-scale test.

\begin{tabular}{|c|c|c|c|c|}
\hline \multirow{2}{*}{ Parameter } & \multicolumn{3}{|c|}{ Location } & \multirow{2}{*}{ Instrumentation } \\
\cline { 2 - 5 } & Ambient & Formwork & Buffer & Thermocouple \\
\hline Temperature & $\mathrm{x}$ & & $\mathrm{x}$ & Anemometer \\
\hline Wind velocity & $\mathrm{x}$ & & & Humidity probe \\
\hline Relative humidity & $\mathrm{x}$ & & & LVDT \\
\hline Displacement & & $\mathrm{x}$ & $\mathrm{x}$ & Strain gauge \\
\hline Deformation & & $\mathrm{x}$ & $\mathrm{x}$ & \\
\hline
\end{tabular}



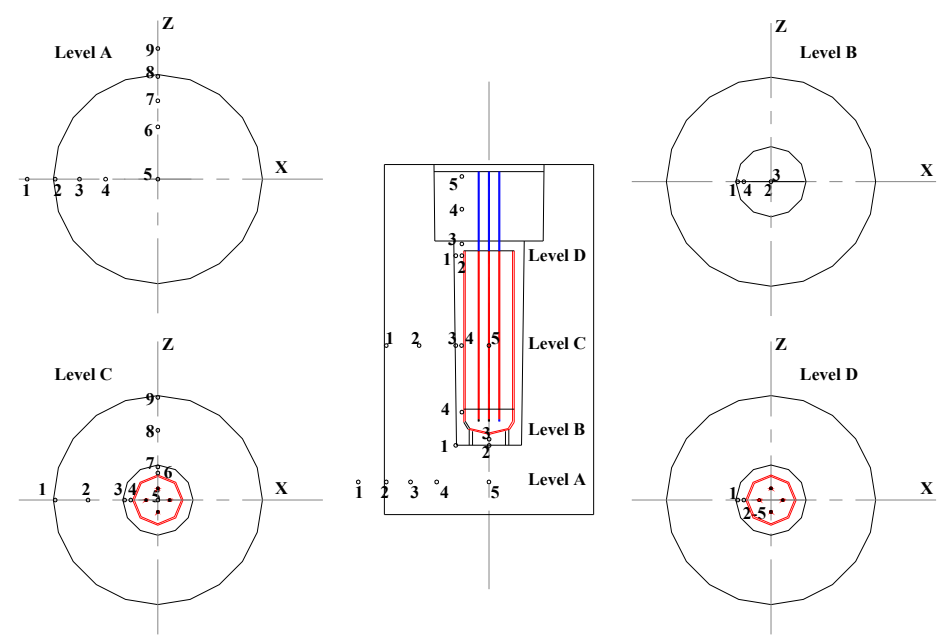

Fig. 6. Typical instrumentation plan showing location of thermocouples.

\section{Test setup}

Figure 7 shows the inner and outer moulds during the test setup. The mould consists of a cylindrical-shape metal construction and includes an outer envelope, a base floor and an inner double cylindrical section with a tapered conical form to facilitate demoulding. The outer envelope consists of two symmetrical half-cylindrical steel sections that attach to each other and to the base by means of bolts. The cylindrical sections measure $3.55 \mathrm{~m}$ in height; have a diameter of $2.11 \mathrm{~m}$ and a wall thickness of $5 \mathrm{~mm}$. The metal base floor has a diameter of $2.31 \mathrm{~m}$ and a thickness of $12.5 \mathrm{~mm}$. The base floor stays permanently attached to the test structure while the rest of the formwork is reusable.
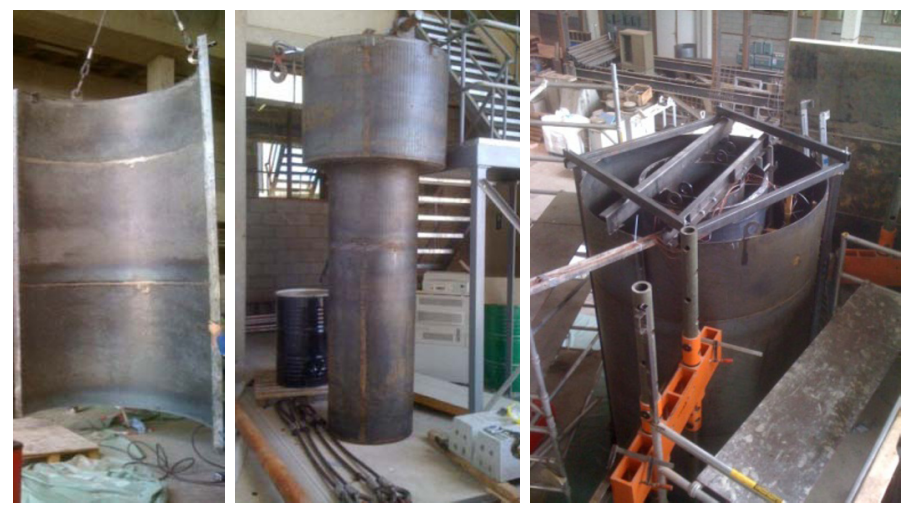

Fig. 7. [Left] one of the cylindrical sections of the outer mould, [middle] inner mould and [right] assembled mould ready for casting of buffer phase 1 .

\section{Test execution}

A chronological sequence of the main stages of the test appears in Table 3. In total the test lasted 150 days, divided in approximately 90 days of curing, 35 days of heating and 20 days of cooling. 
Table 3. Chronology for the half-scale test.

\begin{tabular}{|c|c|c|c|c|c|c|}
\hline \multirow{2}{*}{ Event } & \multirow{2}{*}{ Task } & \multicolumn{5}{|c|}{ Days } \\
\hline & & $0 \quad 30$ & 60 & 90 & 120 & 150 \\
\hline \multirow{4}{*}{ Stage 1} & Casting buffer 1 & $\boldsymbol{\Lambda}$ & & & & \\
\hline & Ambient curing & - & & & & \\
\hline & Removal inner mould & $\boldsymbol{\Delta}$ & & & & \\
\hline & Removal outer mould & $\boldsymbol{\Lambda}$ & & & & \\
\hline Stage 2 & Insert hot overpack & \multicolumn{5}{|c|}{$\boldsymbol{\Delta}$} \\
\hline Stage 3 & Cast filler & \multicolumn{5}{|c|}{$\boldsymbol{\Delta}$} \\
\hline Stage 4 & Cast lid & \multicolumn{5}{|c|}{$\boldsymbol{\Lambda}$} \\
\hline Heating & Heating period & \multicolumn{5}{|c|}{ 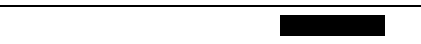 } \\
\hline Heat OFF & End of heating & \multicolumn{5}{|c|}{$\Delta$} \\
\hline Cooling & Cooling period & \multicolumn{5}{|c|}{ 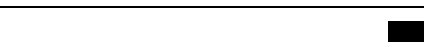 } \\
\hline End of test & Stop test & & & & & \\
\hline
\end{tabular}

\section{Main conclusions}

The results of the half-scale test provided an important contribution to the SC construction feasibility program. The test also provided an opportunity to learn from a number of shortcomings that had not been anticipated before the test. One of the shortcomings was the fact that the aggregates were stored outside, in large stockpiles which made it difficult to correctly measure their water content prior to mixing. As a result, the amount of water and plasticizer required several adjustments during mixing to achieve the necessary slump flow. In future testing, it is advised to use dry aggregates in order to properly control the dosing of water and plasticizer.

There was generally good agreement between the test data and the computer simulations performed using the finite element program HEAT/MLS [4]. This was especially true of the temperature evolution in the outer buffer and the expansive behaviour of the outer concrete buffer, as shown in Figure 8.
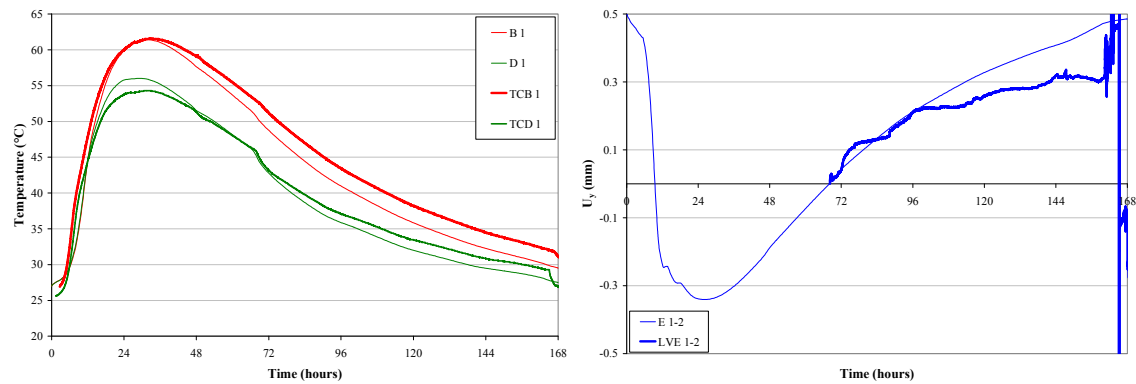

Fig. 8. Simulated (thin line) and measured (thick line) results of temperature [left] and displacement [right] for different locations in the outer concrete buffer [3].

A visual inspection of the outer buffer before introducing the heater in the second phase of the test (Table 2) did not reveal the presence of cracking on the concrete surface. However, microcracks were noticed during the heating period, as shown in Figure 9. The microcracks are barely seen with the naked eye and were likely to have been created by desiccation. Further investigations indicated that the microcracks penetrated less than $5 \mathrm{~mm}$ into the concrete structure. In addition, longitudinal cracks were observed along two sections of the buffer where a wooden structure had been installed to hold instrumentation during the casting of the buffer (Figure 9). 

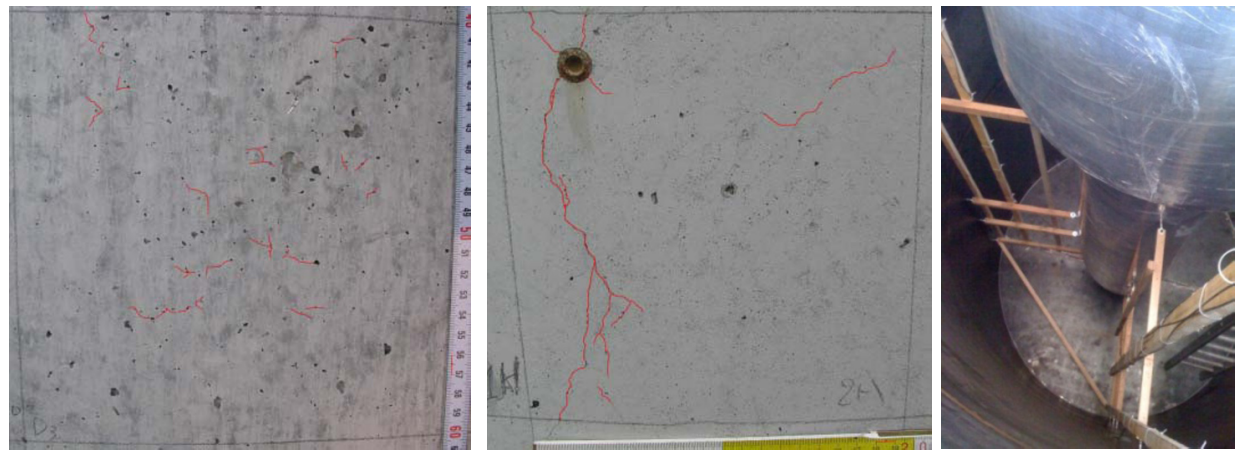

Fig. 9. [Left] typical microcracks observed on a $20 \mathrm{~cm} \times 20 \mathrm{~cm}$ area at the surface of the outer buffer during the heating phase. [Middle] vertically-aligned cracks generated by the wooden structure [right] used to fix the instrumentation in the buffer. The microcracks are highlighted to enhance visibility.

In future testing, instruments cast in the concrete should be fixed using a lighter support structure, for example using a thin metal wire, to avoid cracking of the buffer.

Cut-out sections of the $1 / 2$-scale test carried out six months after completion of the test appear in Figure 10.
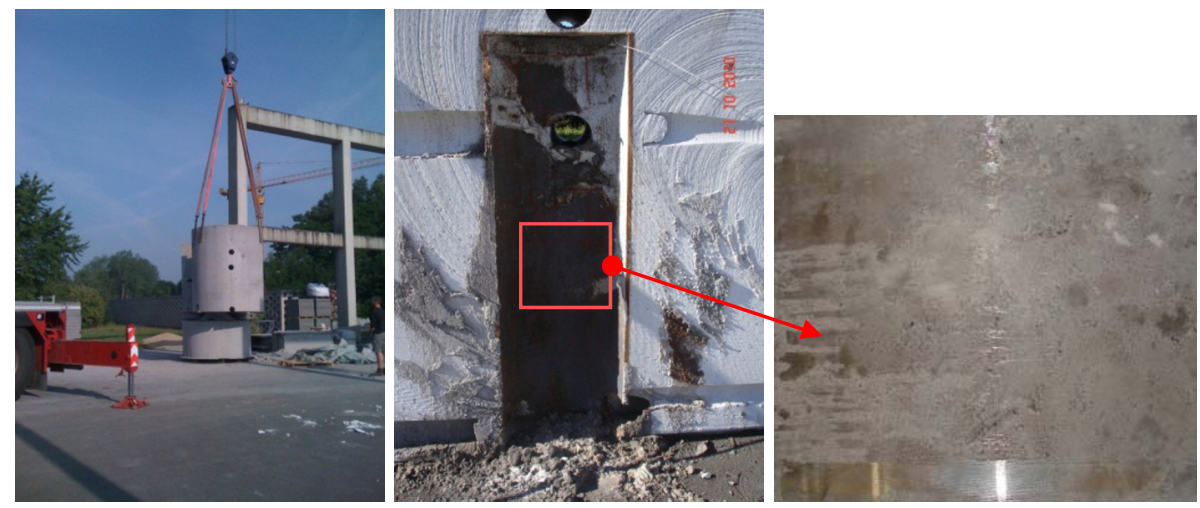

Fig. 10. [Left] $1 / 2$-scale test after cutting out a section for observations. [Middle] cut-out section through centre of overpack and buffer. [Right] removed carbon steel sample with side in contact with the concrete buffer 6 months after the test shows no signs of oxidation.

The left picture in Figure 10 shows a cut-out section of the $1 / 2$-scale test being removed for observations and post-test analyses of the concrete buffer and the carbon steel overpack. Observations of the concrete section performed by naked eye showed no signs of inner cracking. The middle picture shows the cut-out section and part of the carbon steel overpack. The dark colour visible on the inside of the steel overpack is the product of oxidation. The picture to the right is a sample of the carbon steel showing the opposite side of the overpack. This side of the steel was in contact with the concrete and shows no signs of corrosion. This confirms the existence of the high alkaline conditions generated by the concrete and the passivation of the carbon steel surface. 


\section{References}

1. ONDRAF/NIRAS (2009). The Long-Term Safety Strategy for the Geological Disposal of Radioactive Waste, ONDRAF/NIRAS report NIROND-TR 2009-14 E

2. ONDRAF/NIRAS (2010). Feasibility strategy and Feasibility Assessment Methodology for the geological disposal of radioactive waste, ONDRAF/NIRAS report NIROND-TR 2010-19

3. Areias, L., Craeye, B., De Schutter, G., Van Humbeeck, H., Wacquier, W., Villers, L., Van Cotthem, A. (2010). Half-scale test: an important step to demonstrate the feasibility of the Belgian superconatiner concept for disposal of HLW. Proceedings $13^{\text {th }}$ International Conference on Environmental Remediation and Radioactive Waste Management, ICEM2010, Tsukuba, Japan. 4. Craeye, B. (2010). Early-age thermo-mechanical behavior of concrete supercontainers for radwaste disposal, PhD thesis, Ghent University, Belgium. 
